\title{
Integrating Genetic Services into Primary Care: Barriers and Benefits
}

\author{
Safina Adatia \\ News Reporter (HSI 2014-2015)
}

Developments in genetic research are increasing at an alarming rate, and access to genetic information and testing are now more readily available than ever before ${ }^{1}$. In addition, genetic testing has received a significant amount of media attention resulting in greater public awareness ${ }^{2}$. Advances in medical genetics means that patients who are at risk for genetic conditions can be more readily identified, making disease prevention a priority ${ }^{3}$. Such increases in demand for genetic testing have raised concerns regarding specialist availability ${ }^{4}$. A potential solution to this 'supply and demand' problem is the integration of genomic testing into primary care. Family physicians are often the first point of contact, and patients seek out their primary care providers (PCPs) for information and guidance with regard to genetic testing results.

Primary care is largely focused on prevention and health promotion and is an integral part of maintaining a successful healthcare system ${ }^{5}$. Countries with strong systems see patients with improved health outcomes, reduced all-cause mortality and health disparities, and lower health services $\operatorname{costs}^{5}$. Moreover, countries with healthcare systems that are strongly oriented towards primary care tend to offer more equitable and accessible care ${ }^{6}$. Finally, it is estimated that almost $50 \%$ of all visits to physicians are to $\mathrm{PCPs}^{7}$, indicating that they have the greatest accessibility in terms of the patient population.

Since PCPs typically have the largest patient contact, incorporating the use of genetic testing and service provision into primary care could be the ideal solution for the increased awareness and demand for genetic services. For some genetic conditions, such as familial cancers (e.g. breast cancer), preventative genetic testing performed by PCPs can decrease the burden faced by genetic counselors and geneticists ${ }^{8}$. Furthermore, family physicians that have knowledge of a patients' genetic profiles can administer medications more effectively ${ }^{9}$, and have a greater impact on treatment plans ${ }^{8}$. Dr. Gillian Bartlett, Associate Professor at McGill University, focuses her research on the positive impact of implementing genetic services into primary care and works to make this integration possible. According to Dr. Bartlett, a potential area where PCPs can play a critical role is in targeted screening or therapeutics for patients. "Family physicians are already seeing patients who have results from direct-to-consumer genetic testing and are looking for more information. The same thing is also now happening with breast cancer risk and will soon spill over into other chronic diseases and their treatments," says Bartlett.

However, integration of genomic services into primary care settings also presents some significant challenges. While many agree that family physicians are in a unique position to offer genetic services to their patients, quite a few barriers exist. A systematic review conducted by Mikat-Stevens et al. (2014) reviewed the literature associated with family physicians' perceived barriers regarding genetic service provision ${ }^{3}$. According to the review, a lack of general genetic knowledge has been cited as the most common barrier that exists for PCPs ${ }^{3}$. This may include a lack of confidence in their general knowledge of genetics ${ }^{10}$, and a lack of confidence in being able to take an accurate and detailed family history ${ }^{11,12}$.

As the results of genetic testing are quite specific, a further challenge that needs to be considered is the clinical utility of the results. Vasiliki Rahimzadeh, a PhD student in Family Medicine at McGill University, says this barrier exists because of "the nature of what primary care aspires to do and what genomic testing promises to do." According to Rahimzadeh, "primary care is a generalist practice while genomic testing can be very specific, and the links between some genetic determinants of disease are unknown, particularly for chronic diseases." For example, genetic testing that screens for diseases such as cystic fibrosis or chromosomal disorders such as Down's syndrome are relevant to primary care practice; however, testing for genetic markers for Alzheimer's disease is not recommended, as treatment plans do not currently exist and interpretation of results are still uncertain $^{13}$. 


\section{HeALTH SCIENCE INQUiRY}

Dr. June Carroll, a family physician based at Toronto's Mount Sinai Hospital and an Associate Professor at the University of Toronto, is an example of a physician whose goal is to increase genetic literacy among PCP's. She is Co-Director of Genetics Education Canada-Knowledge Organization (GEC-KO), which has developed a website (www.geneticseducation. ca) geared towards PCP's to provide a wealth of tools that PCP's can access. Specifically, these tools aim to guide PCPs in helping their patients navigate genetic testing and determine when it is appropriate to refer their patients for genetic counseling and/or testing. All products featured on the website are primary care-friendly and evidence-based. Based on her research, Dr. Carroll has determined that PCPs see the value of genetic testing, and its foreseeable integration into primary care, however recognizes that "they want a credible source of information and would love to have risk assessment and clinical support tools in genomic medicine integrated into the electronic medical record."

It is inevitable that genetic testing and consultation will enter the realm of primary care. In fact, it already has. PCPs will therefore need to improve their genetic literacy and skills associated with genetic screening. PCPs can help their patients navigate appropriate genetic testing, interpret results from both direct-to-consumer and hospital-based testing, and identify genetic risk factors for certain diseases. However, incorporating genomic services into primary care is not without its challenges. There is a need to identify the most effective ways of integrating genetic services into primary care in order to provide optimal patient-centred care.

\section{References}

1. Carroll JC, Rideout AL, Wilson BJ, Allanson JM, Blaine SM, Esplen MJ, et al. Genetic education for primary care providers: improving attitudes, knowledge, and confidence. Can Fam Physician. 2009;55(12):e92-9.

2. Etchegary H, Cappelli M, Potter B, Vloet M, Graham I, Walker M, et al. Attitude and knowledge about genetics and genetic testing. Public Health Genom. 2010;13(2):80-8.

3. Mikat-Stevens NA, Larson IA, Tarini BA. Primary-care providers perceived barriers to integration of genetics services: a systematic review of the literature. Genet Med. 2015;17:169-76.

4. Touchette N, Holtzman N, JG. D, S. F. Toward the 21st century - incorporating genetics into primary health care. New York, NY: Cold Spring Harbor Laboratory Press; 1997.

5. Starfield B, Shi L, Macinko J. Contribution of primary care to health systems and health. Milbank Q. 2005;83(3):457-502.

6. Atun N. What are the advantages and disadvantages of restructuring a health care system to be more focused on primary care services? Copenhagen: WHO Regional Office for Europe 2004.

7. Petterson SM, Liaw WR, Phillips RL, Rabin DL, Meyers DS, Bazemore AW. Projecting US Primary Care Physician Workforce Needs: 2010-2025. Annals Fam Med. 2012; 10(6):503-9.

8. Bartlett G, Rahimzadeh V, Longo C, Orlando LA, Dawes M, Lachaine J, et al. The future of genomic testing in primary care: the changing face of personalized medicine. Pers Med. 2014; 11(5):477-86.

9. Pulley JM, Denny JC, Peterson JF, Bernard GR, Vnencak-Jones CL, Ramirez $\mathrm{AH}$, et al. Operational implementation of prospective genotyping for personalized medicine: the design of the Vanderbilt PREDICT project. Clin Pharmacol Ther. 2012;92(1):87-95.

10. Fuller $M$, Myers $M$, Webb $T$, Tabangin $M$, Prows C. Primary care providers' responses to patient-generated family history. J Genet Couns. 2010;19(1):84-96.

11. Carroll JC, Cappelli M, Miller F, Wilson BJ, Grunfeld E, Peeters C, et al. Genetic services for hereditary breast/ovarian and colorectal cancers - physicians' awareness, use and satisfaction. Community Genet. 2008;11(1):43-51.

12. Al-Habsi H, Lim JN, Chu CE, Hewison J. Factors influencing the referrals in primary care of asymptomatic patients with a family history of cancer. Genet Med. 2008;10(10):751-7.

13. Emery J, Hayflick S. The challenge of integrating genetic medicine into primary care. Brit Med J. 2001;322(7293):1027-30.

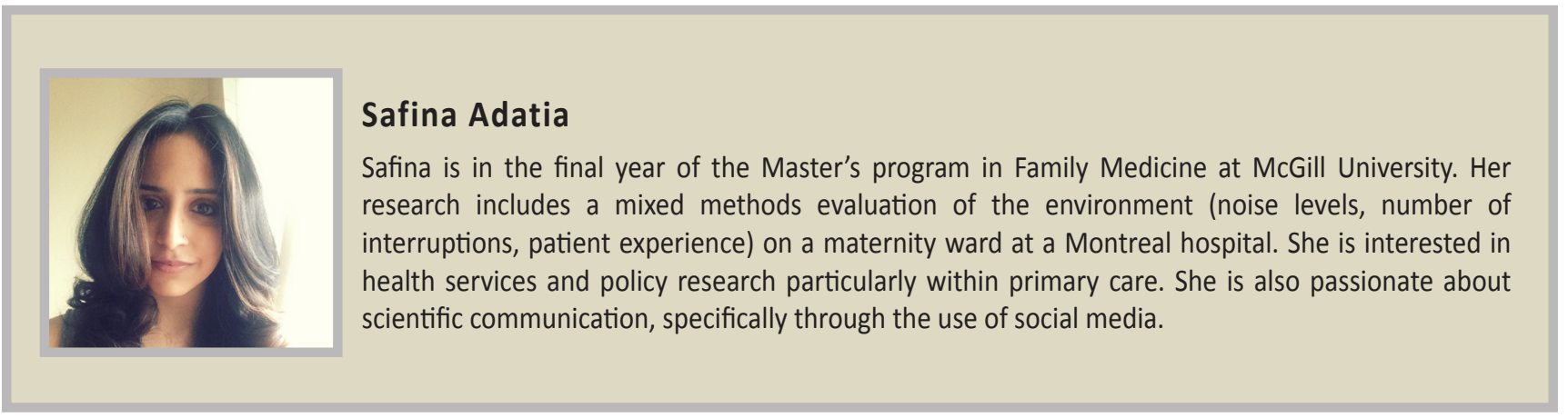

